\title{
Species Abundance and Body Size Relationship of Bird Assemblages at Selected Sites in Western Sarawak
}

\author{
AHMAD FITRI AZIZ* \& CHARLIE JUSTIN MERGIE LAMAN
}

\author{
Faculty of Resource Science and Technology, Universiti Malaysia Sarawak, 94300 Kota Samarahan, Sarawak, \\ Malaysia \\ *Corresponding authors: fitziz61@gmail.com
}

\begin{abstract}
The Energy Equivalence Rule (EER) is an unresolved issue in ecology. This rule states that the amount of energy used for each species in a population is independent of its body size. A study on the relationship between abundance and body size of bird assemblages was conducted in Western Sarawak. Abundance data of bird assemblages from seven selected sites in Western Sarawak were used to produce a regression line of log absolute species abundance versus log average body mass. Data from all selected sites were combined to represent bird assemblages in Western Sarawak and the slope produced was -0.216 . The slopes obtained for each site were 0.808 , $-0.080,-0.258,-0.067,-0.161,-0.072$ and -0.237 , respectively. Statistical analysis shows that the slope of combined data did not differ significantly from -0.75 , as expected under the EER. Thus, this study shows that the EER can be applied as a general rule of community structure of bird assemblages in Western Sarawak.
\end{abstract}

Keywords: Abundance, body size, bird assemblages, energy equivalence rule, regression

Copyright: This is an open access article distributed under the terms of the CC-BY-NC-SA (Creative Commons Attribution-NonCommercial-ShareAlike 4.0 International License) which permits unrestricted use, distribution, and reproduction in any medium, for non-commercial purposes, provided the original work of the author(s) is properly cited.

\section{INTRODUCTION}

Study on the relationship between abundance and body size has been widely examined since it has broad implications on the structure of energy flow in the ecological communities (Illius \& Gordon, 1992). Early studies of this relationship showed a negative regression slope of -0.75 (Damuth, 1981). Damuth (1981) compiled 307 data of terrestrial mammals. By using ordinary least squares (OLS) regression model with both variables logarithmically transformed, the relationship of population density (D) on body mass (M) gave a negative relationship of slope $-0.75, \mathrm{D} \propto \mathrm{cM}^{-0.75}$. Since body weight scales with individual metabolic rate (R) is equal to $0.75, \mathrm{R} \propto \mathrm{cM}^{0.75}$ (Kleiber, 1962), Damuth (1981) has taken this exponent of -0.75 between body size and abundance as evidence for the Energy Equivalence Rule (EER) as a general rule of community structure. These two relationships were assumed inversely proportional to each other (King, 2010). In other words, the abundance of a species is limited by its energetic requirement and each species of different body size in an assemblage used equal amounts of energy that were available in a community (Damuth, 1981; 1987; Nee, Read, Greenwood \& Harvey, 1991). Hence, Peter (1983) suggested that the negative slope of the relationship between abundance and body size is a reflection of the metabolic process where an animal with a larger body size should have lower abundance because it uses more energy per capita per unit time.

The EER remains an unsettled issue in ecology since there were criticisms on these studies (Blackburn et al., 1993). The main criticism is that energy used by all species of all sizes in a community is assumed to be equal (Lawton, 1989). This criticism was supported by the study done on North American birds, which showed that species with larger body size were found to control a larger proportion of resources compared to species with smaller body size (Maurer \& Brown, 1988; Pagel, Harvey \& Godfray, 1991). This is in complete contradiction to the EER. Another criticism is that the algebraic procedure used in the study conducted by Damuth (1981), seems to ignore the variation of slopes across studies (Marquet, Navarette \& Castilla, 1995). The slope of -0.75 was taken to support EER since the relationship between individual metabolic rate and body mass produced a slope of 0.75 (Damuth, 1981). This could be just a coincidence since the comparison was conducted only by visual observation and not by statistical analysis. 
Body size is a basic property of an organism since body size is related to and sometimes used as a convenient measure of lifespan, home range size and other aspects of life history and ecology (Brown, Gillooly, Allen, Savage \& West, 2004; Peter, 1983; White, Ernest, Kerkoff \& Enquist, 2007). Besides that, body size is also one of the primary determinants of metabolism and there is a relationship between the body size and abundance of animal in the ecosystem (White et al., 2007). In the study on the relationship between abundance and body size, body mass is widely used as the body size parameter (Peter, 1983). Body mass is used as the independent variable in the regression analysis of this relationship to predict the abundance of species since body mass always gives a sensible approximation to body size (Gosler, Greenwood, Baker \& Davidson, 1998). Even when the only available measurement of body size was body length, it was first statistically converted to estimate body weight by using an appropriate coefficient from the length-weight regression (Gowing \& Recher, 1984; Rogers, Buschbom \& Watson, 1977; Schoener, 1980). Species abundance is used as the dependent variable where the abundance was estimated using body mass as the predictor.

Blackburn et al. (1993) studied the relationship between abundance and body size in natural animal assemblages. Blackburn et al. (1993) compile nine previously unpublished and five previously published data on animal assemblages. From the 14 assemblages, 12 showed a negative relationship between log abundance and log body size. The 12 negative relationships included the five set of bird assemblage data that were obtained from the abundance data on North American birds (Brown \& Maurer, 1987) and British and Swedish birds (Nee et al., 1991) and British Trust for Ornithology Common Birds Census that were done in woodland and farmland habitats (Marchant, Hudson, Carter \& Whittington, 1990). However, when comparison was made by using the F-test, only the OLS regression line for the British and Swedish bird assemblages (Nee et al., 1991) did not differ significantly from -0.75 . The other 12 assemblages had a slope greater than -0.75 .

Bini, Coelho and Diniz-Filho (2001) summarised the results from the previous studies on the relationship between abundance and body size. They combined 74 slopes of the relationship between population density and body mass of mammals and 53 slopes of birds (Blackburn et al., 1993; Brown \& Maurer, 1987; Carrascal \& Telleria, 1991; Damuth, 1981; Ebenman et al., 1995; Peters, 1983; Nee et al., 1991; Silva, Brown \& Downing, 1997). They found that the combination of these 127 slopes of mammals and birds produced a slope of -0.65 with a variance of 0.00007 . However, when they combined the slopes separately for mammals and birds, the slopes were -0.755 and -0.321 , respectively. Based on these results, Bini et al. (2001) did not argue the validity of EER on mammals since the combination of 74 slopes of mammals still did differ significantly from -0.75 . However, the combination of 53 slopes of birds gave a significant difference with -0.75 .

A more recent study by Russo, Robinson and Terborgh (2003) on body size and abundance relationship of Amazonian bird community found that the slope of the relationship between log population density and log body mass was -0.22 . This was found to be significantly different to the EER expected slope of -0.75 . Field metabolic rate of avian species was estimated in order to produce the relationship between individual metabolic rate and body mass. The relationship between individual metabolic rate and body size for all species in the assemblages shows a significantly positive slope of 0.46 . This relationship does not seem to reflect the relationship between abundance and body size as proposed by the EER. This indicates that population energy used for larger species was greater than for smaller species (Russo et al., 2003).

The results of the relationship between abundance and body size based on the previous studies seem to be unstable (Bini et al., 2001; Blackburn et al., 1993; Russo et al., 2003). This paper reports on the analysis of the relationship between abundance and body size of bird assemblages to gain a better understanding of this relationship.

\section{MATERIALS \& METHODS}

In this study, all the abundance data were obtained from Western Sarawak. Western Sarawak covers an area from Tanjung Datu to Batang Saribas (Kaur, 1995). A total of seven published and unpublished data sets from Western Sarawak were utilised in this study. These data sets include the data of bird abundance in Permai Rainforest Resort Santubong (PRRS), Kubah National Park (KNP), Gunung Gading National Park (GGNP), Bako National Park 
(BNP), Mount Singai (MS), Mount Jagoi (MJ) and Samajaya Nature Reserve (SNR) (Figure1). The mist-netting method was used to capture birds. At least five continuous days of sampling were allocated each data collection in order to standardise the sampling.

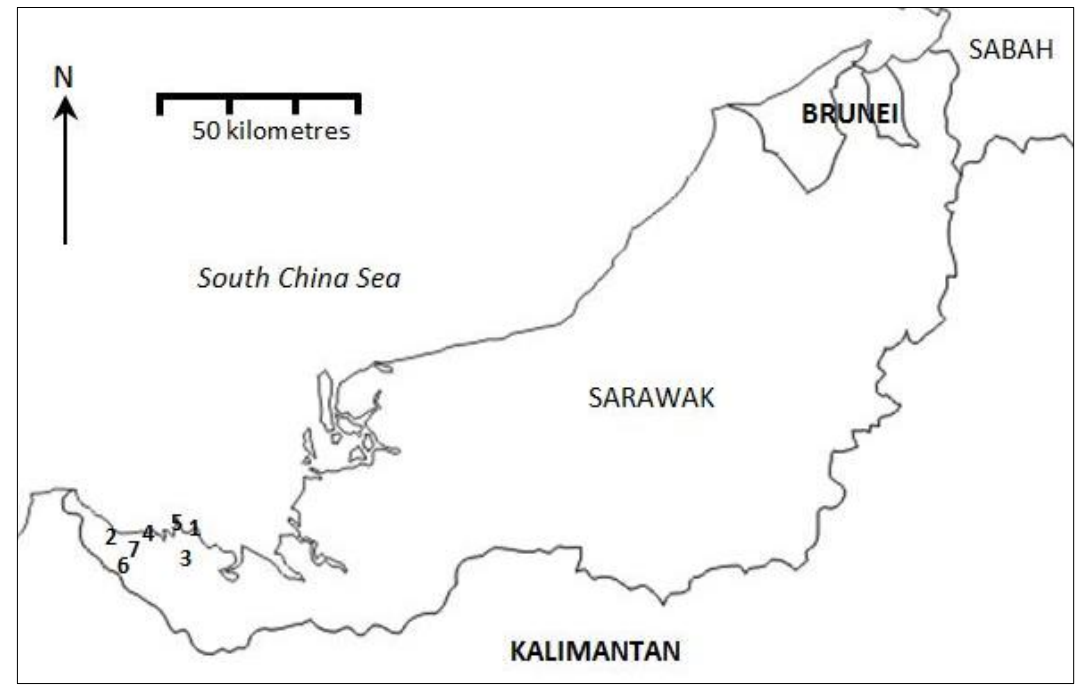

Figure 1. Map of study areas in seven selected sites around Western Sarawak. Bako National Park (1); Gunung Gading National Park (2); Samajaya Nature Reserve (3); Kubah National Park (4); Permai Rainforest Resort Santubong (5); Mount Jagoi (6); Mount Singai (7).

The Statistical Package for the Social Sciences (SPSS) Software Version 21.0 was used to perform correlation and regression analyses in this study. Regression analysis is a statistical technique for modelling the relationship between a dependent variable and one or more independent variables (Lewis-Beck, 1993). The OLS regression model was applied in this study. This model assumes that there is no error variance in the independent variables in the regression analysis (Blackburn \& Gaston, 1996). The study by Damuth (1981) on the relationship between abundance and body size mentioned abundance measured as population density. In the absence of population density data in this study, species abundance data were used as the dependent variable in the OLS regression analysis. The dependent variable was log absolute species abundance. Absolute species abundance was the exact number of individuals per species in the sample. Meanwhile, log average body size was used as the independent variable. Body mass is the measurement used to indicate body size in this study. Average body mass was calculated as:

Average Body Mass = Total body mass of a species

Total number of individuals in a species

Slopes of the regression line of log absolute species abundance (dependent variable) versus log average body mass (independent variable) for each selected study site was produced. Data of bird abundance from these seven sites were combined to represent bird assemblages in Western Sarawak.

Further statistical analysis was done to test whether the slope of the relationship between log absolute species abundance and log average body size produced for each selected site was significantly different from 0.75 . In this analysis, the $t$-test was used with a significance level of $\alpha=0.05$ (one tailed-test). In this study, the data of population density were absent. The only available were species abundance data. The abundance data had to be used as the dependent variable in the regression analysis of the relationship between abundance and body size. In the literatures, some researchers used the total number of individuals in sample, or species abundance as the dependent variable in the regression analysis (Blackburn et al., 1993; Maxwell \& Jennings, 2006; Oindo, 
Skidmore \& Prins, 2001). Meanwhile, most researchers used population density as the dependent variable in the study of the relationship between abundance and body size (Bini et al., 2001; Russo et al., 2003; Silva et al., 1997).

There are two main reasons to test the significant difference of the slope produced with -0.75 . The first is to confirm whether the regression slope produced by the log absolute species abundance on log average body mass for each study site can be used as evidence to support the EER. If it is significantly different from -0.75 , then the result of this study cannot be used to support the EER as proposed by Damuth (1981). The second reason is to test whether species abundance (A) can be used instead of population density (D) as the dependent variable in the regression analysis.

\section{RESULTS}

The relationship between log absolute species abundance and log average body mass of bird assemblages for seven study sites with various population abundance are presented separately in this study. Subsequently, all seven sites were combined to represent a relationship between log absolute species abundance and log average body mass of bird assemblages for Western Sarawak, as shown in Table 1.

Table 1. Regression statistical value of the relationship between log species abundance and log average body size of bird in seven data sets.

\begin{tabular}{ccccccc}
\hline Data Set & $\mathbf{n}$ & $\mathbf{r}$ & $\boldsymbol{\beta}$ & $\mathbf{S E}$ & $\boldsymbol{p}$-value & $\mathbf{9 5 \%} \mathbf{C I}$ \\
\hline BNP & 9 & 0.453 & 0.808 & 0.321 & 0.221 & $(-0.614,2.230)$ \\
GGNP & 37 & 0.070 & -0.080 & 0.349 & 0.681 & $(-0.472,0.312)$ \\
MJ & 52 & 0.205 & -0.258 & 0.434 & 0.144 & $(-0.607,0.091)$ \\
KNP & 29 & 0.052 & -0.067 & 0.392 & 0.788 & $(-0.576,0.441)$ \\
SNR & 9 & 0.385 & -0.161 & 0.149 & 0.307 & $(-0.507,0.184)$ \\
PRRS & 7 & 0.103 & -0.072 & 0.252 & 0.826 & $(-0.876,0.731)$ \\
MS & 19 & 0.213 & -0.237 & 0.359 & 0.381 & $(-0.792,0.319)$ \\
Western Sarawak & 91 & 0.150 & -0.216 & 0.157 & 0.157 & $(-0.516,0.085)$ \\
\hline
\end{tabular}

Note: $\mathrm{n}$ is the number of species found in every site. $r$ (correlation coefficient) is the amount of variance in abundance explained by the correlation with body size across all species in each assemblage. $\beta$ is the regression slope through all species in each assemblage. The standard error (SE) and $95 \%$ confidence interval of each slope are given. $p$-value used in the $t$-test to determine if there is any significant difference.

The correlation coefficients $(r)$ for these relationships, together with the slopes of the regression lines for these data, the standard error of the estimates, the $p$-values and 95\% confidence intervals are given in Table 1 . The combined species abundance data from all seven study sites shows a negative relationship of log absolute species abundance versus log average body size (Figure 2a). The $r$ value for the combination set is 0.150 , which is less than $0.2(r<0.2)$ indicating that the body size explains less than $20 \%$ of the of the data variation in abundance.

Data sets from GGNP, MJ, KNP, SNR, PRRS and MS show negative slopes for the relationships between $\log$ absolute species abundance and log average body size. Only the data set from BNP shows a positive slope on log absolute species abundance versus log average body size (Figure 2). GGNP, KNP and PRRS produced $r$ values 
less than $0.2(r<0.2)$. The value of less than 0.2 indicate that the body size explained less than $20 \%$ of the variation in the abundance.

The SNR and MS show $r$ values greater than $0.2(r>0.2)$ which indicate that the body size explains more than $20 \%$ of the variation in the abundance. BNP is the only data set to show $r$ value greater than $0.4(r>$ 0.4 ). This indicates that more than $40 \%$ of the variation in the abundance was explained by the body size. Although slopes $(\beta)$ produced in each study site are greater than -0.75 (less negative) and one of the data set shows a positive slope, all the data sets show no significant difference with -0.75 , including the combined data set when comparison was made by using the $t$-test. The $p$-values for all data sets are greater than 0.05 significance level ( $p$ $>0.05)$ in the one-tailed test.

\section{DISCUSSION}

As expected under the EER by Damuth (1981), the relationship between abundance and body size gives a negative slope where species with larger body size tend to live at lower abundance compared to species with smaller body size. In order to represent the bird assemblages in Western Sarawak, the abundance data of bird assemblages from the seven study sites were combined. The slope for the combined data was -0.216 .

When the regressions between log absolute species abundance and log average body size were performed separately, the regression slopes produced in six out of seven assemblages show negative values. The data sets in GGNP, MJ, KNP, SNR, PRRS and MS produced slopes of -0.08, -0.259, -0.067, -0.161, -0.072, -0.237 and 0.216 , respectively. Two assumptions were made from these negative relationships. First, these negative relationships indicate that birds of larger body size lived at lower abundance compared to birds of smaller body size in the assemblages. Second, equal amount of energy is being used by birds of different body size in the assemblages.

However, confusion may have occurred regarding the dependent variable being used in the regression analysis of the relationship between abundance and body size (Blackburn et al., 1993; Harvey, 1982; Harvey \& Lawton, 1986; Nee, Harvey \& Cotgreave, 1992). There are arguments on how Damuth (1981) was able to use population density as the dependent variable in the regression analysis of the relationship between abundance and body size since the data used in the study did not come from the whole local assemblages of one habitat. However, it came from the literature (Brown \& Maurer, 1987; Lawton, 1989; 1991; Morse, Stork \& Lawton, 1988). The data sets were the compilation of the abundance of species aggregated at the continental or global scale, which were then converted into density (Blackburn \& Gaston, 1996). Blackburn and Gaston (1996) further argued that the dependent variable used by Damuth (1981) was impractical, as the population density were gathered from different part of the continents, which probably the animals were not interacting with each other.

Even if there is a method to measure population density across continents or at the global scale, there is still a problem that Damuth (1981) might have overlooked: the data samples, which came from the literature probably ignored the number of small species and rare species (Brown \& Maurer, 1987; Lawton, 1989; 1991; Morse et al., 1988). These densities might be biased toward the maximum population densities because ecologists tend to study populations where they are abundant (Blackburn et al., 1993). Although, there are criticisms and debates regarding this problem, the relationship between abundance and body size is still the most attractive measure of how the energy equivalence is explained (Currie, 1993). Indeed, the relationship between abundance and body size has been cited as a good model of a general ecological rule (Peter, 1991).

It is inappropriate to use the literature as evidence to enable the usage of species abundance as a variable in the regression analysis of this relationship. Thus, $t$-test was used to test the significant difference of the slope produced with -0.75 . There is no doubt in the usage of species abundance data as the dependent variable in the OLS regression analysis of the relationship between abundance and body size since the $t$-test provided the evidence that there is no significant difference in the usage of population density or species abundance. 


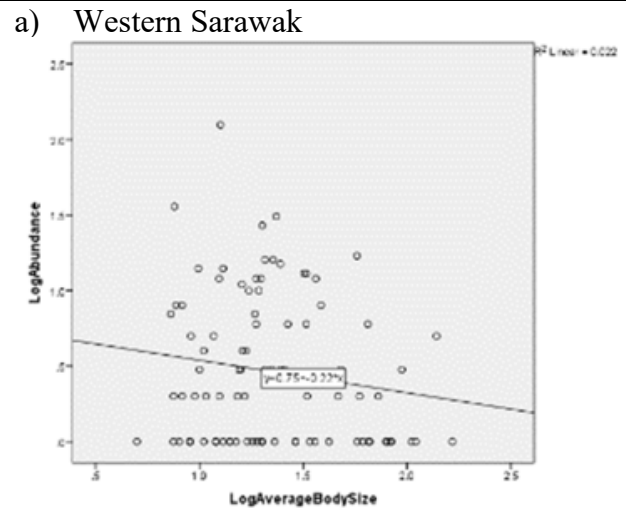

c) GGNP

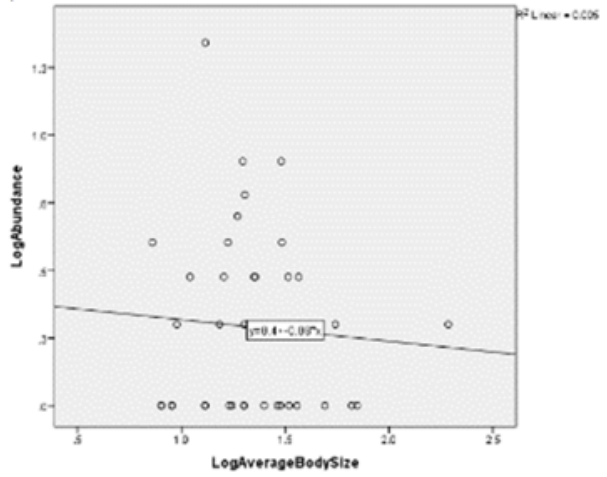

e) $\mathrm{KNP}$

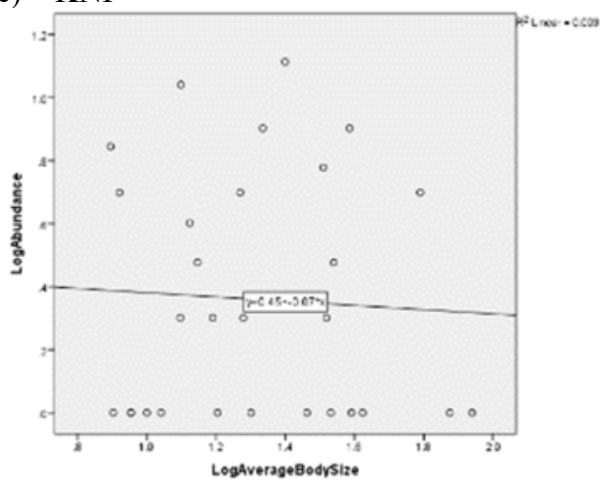

g) PRRS

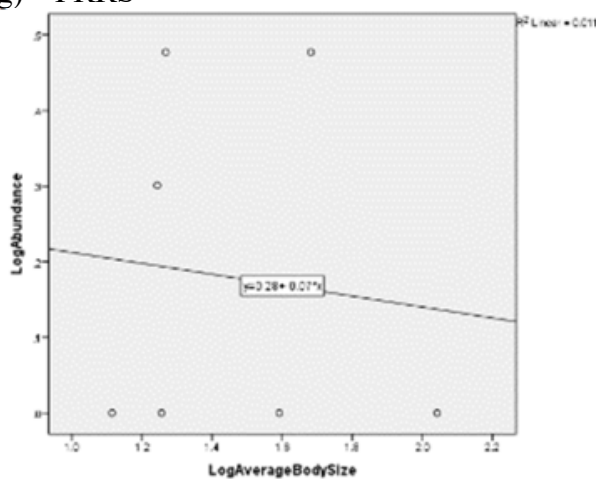

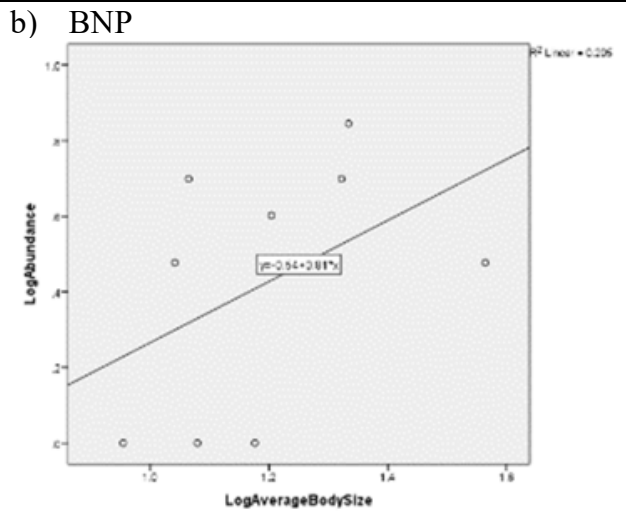

d) $\mathrm{MJ}$

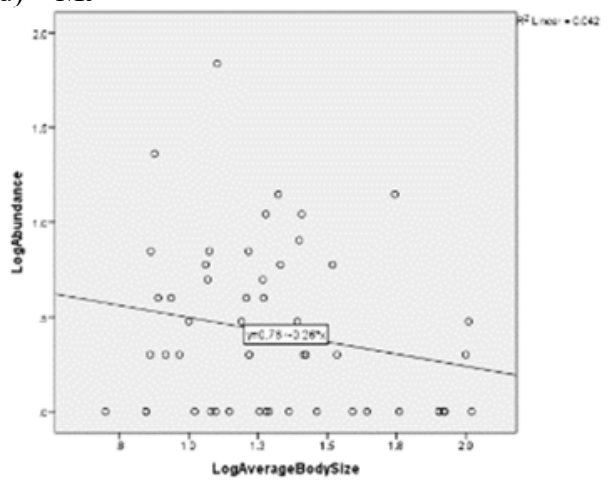

f) SNR

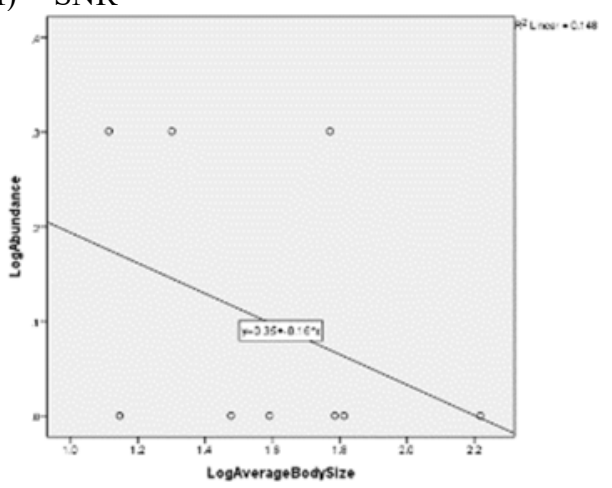

h) MS

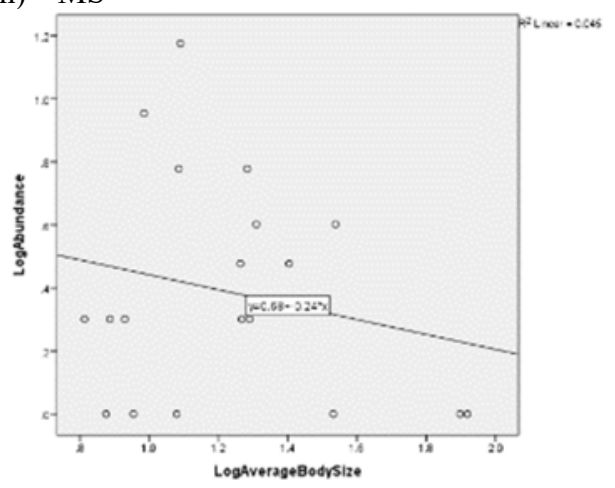

Figure 2. Correlation between log absolute species abundance (total number of individuals per species in sample) and log average body size (weight) of bird assemblages. 


\section{CONCLUSION}

The relationship between log absolute species abundance and log average body size of bird assemblages for all sites show slopes not significantly different from -0.75 . The combined data of bird assemblages from all seven study sites show a negative relationship with regression slope of -0.216 . Since the slope produced for the combined data sets, used to represent bird assemblages in Western Sarawak, did not differ significantly from -0.75 , this study can be taken as evidence to support EER as a general rule of community structure and body size is a good predictor of bird abundance in Western Sarawak.

\section{ACKNOWLEDGEMENTS}

We would like to acknowledge the Institute of Biodiversity and Environment Conservation (IBEC), UNIMAS, for providing data for analysis and equipment for sampling, in lieu of performing this study.

\section{REFERENCES}

Bini, L. M., Coelho, A. S. G. \& Diniz-Filho, J. A. F. (2001). Is the relationship between population density and body size consistent across independent studies? a meta-analytical approach. Brazilian Journal of Biology, 61, 1-6.

Blackburn, T. M., Brown, V. K., Doube, B. M., Greenwood, J. J. D., Lawton, J. H. \& Stork, N. E. (1993). The relationship between abundance and body size in natural animal assemblages. Journal of Animal Ecology, 62, 519-528.

Blackburn, T. M. \& Gaston, K. J. (1996). Abundance-body size relationship: the area you census tell you more. Oikos, 75, 303-309.

Brown, J. H., Gillooly, J. F., Allen, A. P., Savage, V. M. \& West, G. B. (2004). Toward a metabolic theory of ecology. Ecology, 85, 1771-1789.

Brown, J. H. \& Maurer, B. A. (1987). Evolution of species assemblages: effects of energetic constraints and species dynamics on the diversification of the North American avifauna. American Naturalist, 130, 1-17.

Carrascal, L. M. \& Tellería, J. L. (1991). Bird size and density: a regional approach. American Naturalist, 138, 777-784.

Currie, D. J. (1993). What shape is the relationship between body size and population density. Oikos, 66, 353358.

Damuth, J. (1981). Population density and body size in mammals. Nature, 290, 699-700.

Damuth, J. (1987). Interspecific allometry of population density in mammals and other animals: the independence of body mass and population energy use. Biological Journal of the Linnean Society, 31, 193-246.

Ebenman, B., Hedenstrom, A., Wennergren, U., Ekstam, B., Landin, J. \& Tyrberg, T. (1995). The relationship between population density and body size: the role of extinction and mobility. Oikos, 73, 225-230.

Gosler, A. G., Greenwood, J. J. D., Baker, J. K. \& Davidson, N. C. (1998). The field determination of body size and condition in passerines: a report to the British ringing committee. Bird Study, 45, 92-103.

Gowing, G. \& Recher, H. F. (1984). Length-weight relationships for invertebrates from forests in south-eastern New South Wales. Australian Journal of Ecology, 9, 5-8.

Harvey, P. H. (1982). Comparisons between taxa and adaptive trends. In: Current problem in sociobiology. Cambridge University Press, Cambridge. Pp 343-361.

Harvey, P. H. \& Lawton, J. H. (1986). Patterns in three dimensions. Nature, 324(6094), 212.

Illius, A. W. \& Gordon, I. J. (1992). Modelling the nutritional ecology of ungulate herbivores: evolution of body size and competitive interaction. Oecologia, 89, 428-434.

Kaur, A. (1995). The babbling Brookes: economics change in Sarawak 1841-1941. Modern Asian Studies, 29(1), 65-109.

King, J. R. (2010). Size-abundance relationships in Florida ant communities reveal how ants break the energetic equivalence rule. Ecological Entomology, 35, 287-298.

Kleiber, M. (1962). The Fire of Life. Wiley, New York.

Lawton, J. H. (1989). What is the relationship between population density and body size in animal? Oikos, 55, 429-434. 
Lawton, J. H. (1991). Species richness and population dynamics of animal assemblages. Patterns in body-size: abundance space. Philosophical Transaction of the Royal Society, 330, 283-291.

Lewis-Beck, M. S. (1993). International handbooks of quantitative applications in the social sciences. Sage Publications.

Marchant, J. H., Hudson, R., Carter, S. P. \& Whittington, P. (1990). Population Trends in British Breeding Birds. British Trust for Ornithology, Tring, Hertfordshire.

Marquet, P. A., Navarette, S. A. \& Castilla, J. C. (1995). Body size, population density and the energetic equivalence rule. Journal of Animal Ecology, 64, 325-332.

Maurer, B. A. \& Brown, J. H. (1988). Distribution of energy use and biomass among species of North America terrestrial birds. Ecology, 69, 1923-1932.

Maxwell, T. A. D. \& Jennings, S. (2006). Predicting abundance-body size relationship in functional and taxonomic subsets of food webs. Oecologia, 150, 282-290.

Morse, D. R., Stork, N. E. \& Lawton, J. H. (1988). Species number, species abundance and body length relationships of arboreal beetles in Bornean lowland rain forest trees. Ecological Entomology, 13, 25-37.

Nee, S., Read, A. F., Greenwood, J. J. D. \& Harvey, P. H. (1991). The relationship between abundance and body size in British birds. Nature, 351, 312-313.

Nee, S., Harvey, P. H. \& Cotgreave, P. (1992). Population persistence and the natural relationships between body size and abundance. In: Conservation of Biodiversity for sustainable developments (Sandlund, O. T., Hindar, K. \& Brown, A. H. D., Eds.). Scandinavian University Press, Oslo. Pp 124-136.

Oindo, B. O., Skidmore, A. K. \& Prins, H. H. T. (2001). Body size and abundance relationship: an index of diversity for herbivores. Biodiversity and Conservation, 10, 1923-1931.

Pagel, M. D., Harvey, P. H. \& Godfray, H. C. J. (1991). Species abundance, biomass and resource use distributions. American Naturalist, 138, 836-850.

Peter, R. H. (1983). The ecological implications of body size. Cambridge University Press, United Kingdom. Pp 329.

Peters, R. H. (1991). A critique for ecology. Cambridge University Press, Cambridge.

Rogers, L. E., Buschbom, R. L. \& Watson, C. R. (1977). Length-weight relationships of shrub-steppe invertebrates. Annals of the Entomological Society of America, 70, 51-53.

Russo, S. E., Robinson, S. K. \& Terborgh, J. (2003). Size-abundance relationships in an Amazonian bird community: implications for the energetic equivalence rule. American Naturalist, 161, 267-283.

Schoener, T. W. (1980). Length-weight regressions in tropical and temperate forest understorey insects. Annals of the Entomological Society of America, 73, 106-109.

Silva, M., Brown, J. H. \& Downing, J. A. (1997). Differences in population density and energy use between birds and mammals: a macroecological perspective. Journal of Animal Ecology, 66, 327-340.

White, E. P., Ernest, S. K. M., Kerkoff, A. J. \& Enquist, B. J. (2007). Relationships between body size and abundance in ecology. Trends in Ecology and Evolution, 22, 323-330. 